\section{LA INFLUENCIA DE ALEJANDRO DE HUMBOLDT EN DOS ARTISTAS VENEZOLANOS DEL SIGLO XIX}

\author{
Roldán Esteva-Grillet \\ Dpto. Artes Plásticas, Escuela de Artes \\ Universidad Central de Venezuela \\ Ciudad Universitaria de Caracas, Los Chaguaramos \\ Caracas, Venezuela
}

\section{ALEXANDER DE HUMBOLDT INFLUENCE IN TWO VENEZUELAN ARTISTS AT CENTURY NINETEENTH}

\begin{abstract}
Throughout century XIX in the Latin American painting several new subjects are introduced, among them the landscape, no longer more like scene of patriotic, religious or costumbristas scenes. The model propose by Alexander de Humboldt in its book Vue de cordillères et monuments des peuples indigènes de l'Amérique, of 1810 , for the scientific study of the landscape, is going to be followed not only by artists German, but by nationals like Car it to me the Fernandez Páez and Ramon Bolet Peraza who will approach modestly in their work to the watercolor and the weather. First in its character of illustrator of the geographic work of Agustin Codazzi, as much in Venezuela as in Colombia, the second when taking care of requests of foreign retailers but also by their participation in scientific expeditions. The study of these two nineteenth-century, devoid artists of a properly academic formation, does not open a possibility of valuation for other artists who did not get to compete in European Halls and were either in its time very solicited like retratists.
\end{abstract}

KEY WORDS: Nature; Science; Landscape; Alexander de Humboldt; Car it to me Fernandez; Ramon Bolet.

La pintura de paisaje es no menos que una descripción fresca y animada, propia a difundir el estudio de la naturaleza.

(Alejandro Humboldt, Cosmos, 1845)

\section{Preámbulo}

El paisaje como género pictórico tuvo en Venezuela una lenta aparición a lo largo del siglo XIX. En la historiografía artística latinoamericana ha sido unánime el reconocimiento del naturalista alemán Alejandro de Humboldt (1769-1859) como la figura más influyente en el desarrollo del género paisajístico, por la presencia de varios pin-
RESUMEN: A lo largo del siglo XIX en la pintura latinoamericana se introducen varios temas nuevos, entre ellos el paisaje, ya no más como escenario de escenas patrióticas, religiosas o costumbristas. El modelo propuesto por Alejandro de Humboldt en su libro Vue des cordillères et monuments des peuples indigènes de l'Amérique, de 1810, para el estudio científico del paisaje, va a ser seguido no sólo por artistas alemanes, sino por nacionales como Carmelo Fernández Páez y Ramón Bolet Peraza quienes abordarán modestamente en su obra a la acuarela y al temple. El primero en su carácter de ilustrador de la labor geográfica de Agustín Codazzi, tanto en Venezuela como en Colombia, el segundo al atender solicitudes de comerciantes extranjeros pero también por su participación en expediciones científicas. El estudio de estos dos artistas decimonónicos, carentes de una formación propiamente académica, abre una posibilidad de valoración para otros artistas que no llegaron a competir en Salones europeos y tampoco fueron en su tiempo muy solicitados como retratistas.

PALABRAS CLAVE: Naturaleza; ciencia; paisaje; Alejandro de Humboldt; Carmelo Fernández; Ramón Bolet.

tores europeos que atendieron sus consejos y recibieron su protección (Giraldo Jaramillo, 1959, 11-19; Löschner, 1988-1989; Rojas-Mix, 1988, 81-95)'. Entre ellos, destaca muy especialmente el dibujante y pintor al óleo Ferdinand Bellermann (1814-1889), por haber dedicado su arte a la exaltación de la naturaleza venezolana (Rohl, 1983, 109-116; Boulton y Löschner, 1977; Boulton y Weissärger, 1991)2. Un segundo artista, de menor resonancia pictórica pero de sumo interés para nosotros, fue el ornitólogo, taxidermista, dibujante y acuarelista Antón Goering (18361905) (Rohl, 1983, 173-213; Dupouy, 1969)33.

Otros visitantes tuvimos a lo largo del siglo XIX, más científicos que artistas, cuya presencia fue estimulada, en 
cierta manera, por la personalidad de Humboldt; bástenos mencionar a Carl Ferdinand Appun (1820-1872) y Hermann Karsten (1817-1908). Por otra parte, para pintores ajenos al ideario y promoción humboldtianos como Fritz Georg Melbye (1826-1869) o el mismo joven Camille Pissarro (1830-1903), la estética prerromántica de lo pintoresco y de lo sublime no contradecía el afán iluminista de registrar científicamente la naturaleza (Pérez Silva y Pino Iturrieta, 1993).

Poca atención se ha dedicado en nuestra historiografía a la influencia de tales ideas en los paisajistas criollos, quienes recurrieron más a la ilustración gráfica que a los cuadros al óleo, y cuya misma producción al temple o a la acuarela resulta exigua por ausencia de un mercado local. Excepcionalmente, el dibujante, litógrafo y miniaturista Carmelo Fernández Páez (1889-1887), tuvo alguna formación en el extranjero -si bien menos dedicado a su arte por su condición de ingeniero militar-; su obra, más cercana a la crónica y a la ilustración científica, resultó escasamente difundida en su época ${ }^{4}$. En tanto que Ramón Bolet Peraza (1836-1876), dibujante autodidacto, acuarelista y fotógrafo, alcanzó un relativo éxito con sus ilustraciones de diversas ciudades y monumentos arquitectónicos así como en la exportación de sus motivos, de los cuales sólo conocemos los títulos 5 .

Ambos experimentaron con las técnicas modernas de la litografía y trabajaron con científicos o exploradores de la naturaleza; asimismo, en la obra de estos dos dibujantes y pintores es posible reencontrar los ideales humboldtianos, tocados ya -más en el segundo que en el primero-, por el objetivismo de la cámara fotográfica y por la captación sentimental del paisaje.

\section{LA TRADICIÓN PICTÓRICA Y EL MUNDO REAL}

Es injusta la opinión que juzga como "limitación impuesta" por las exigencias confesionales, la poca producción de imágenes reales en la tradición pictórica hispanoamericana (Gasparini, 1967; Junquera, 1988, 79-89). Es innegable que la mayor parte del arte colonial obedecía a los propósitos evangelizadores y de conservación de la fe y moral cristianas, a semejanza del arte medieval europeo y buena parte del subsiguiente, desde el Renacimiento hasta el
Neoclasicismo. Sin embargo, no es posible ignorar la existencia -si bien no abundante-, de imágenes que retratan la sociedad y la naturaleza americana como un mundo real: vistas de ciudades, cuadros de castas, fauna y flora local, escenas urbanas y acontecimientos (v.gr. entradas de virreyes, traslados de monjas), sin olvidar los retratos de personalidades civiles, religiosas y militares. Particularmente durante el siglo XVIII, en cierta forma acicateado por el gusto exótico europeo, se acrecienta el deseo de "conocer" ese mundo americano para su mejor provecho.

El Siglo de las Luces fue pues, para América un siglo de desperezamiento, de apertura hacia nuevas ideas, entre ellas la de "inventariar" las riquezas americanas en aras de una modernización en las relaciones comerciales. La imagen de América se apoyaba fundamentalmente en las viejas crónicas y en los grabados europeos, junto a los productos que la tipificaban (Cummins, 1994, I, 17-31). Con la expulsión de los jesuitas de Portugal y Brasil en 1759 y de España y sus colonias en 1767, muchos de ellos divulgaron desde Europa una visión iluminista en la que la multidisciplinariedad científica era la regla. La autoridad o credibilidad se la otorgaba el haber vivido en estas tierras. De allí la importancia del viaje, de la exploración, del constatar con los propios ojos ese mundo desconocido 0 , en todo caso, tergiversado tanto por el celo hispánico como por los contrapuestos intereses políticos de las potencias.

También, el espíritu enciclopedista promovió un interés por divulgar el conocimiento a toda la sociedad, su educación en artes y oficios, su participación en los logros del siglo en cuanto a mejorar los niveles de vida y producción económica. Si en principio eso significaba un "dirigismo centralizado", con la Revolución francesa en 1789, fueron las clases subalternas quienes reclamaron su derecho a la participación en el saber y, por ende, en la conducción de la sociedad.

Un hito fundamental en esta carrera por "inventariar" la América, lo representó la Expedición Botánica del Reino de Nueva Granada entre 1783 y 1816, bajo la dirección del sabio gaditano José Celestino Mutis (1732-1808). Sin duda, el haber tenido que apelar a artistas quiteños para configurar -a través de un sistema casi monacal de trabajo educativo-, un selecto grupo de ilustradores a la acuarela, marca un corte en la tradición pictórica restringida a las imágenes religiosas. La flora será el motivo casi exclusivo 
(Fajardo de Rueda, 1994, I, 207-241). Sin embargo, un artista como Vicente Albán (act. 1780) supera esa limitación ilustrativa y se adentra en una serie de cuadros en los que representa los frutos del Ecuador junto a tipologías sociales, siguiendo de cerca el modelo de los cuadros de castas mexicanos ${ }^{6}$.

Cuando Alejandro de Humboldt emprende su viaje a las regiones equinocciales del Nuevo Mundo, viene provisto de una buena formación académica en el campo del dibujo y del grabado en cobre ${ }^{7}$. Con ella se auxilia en su cuaderno de notas para representar las formas naturales que describe (fig. 1), sean éstas montañas, ríos, animales, plantas 0 monumentos prehispánicos (Humboldt, 1810) ${ }^{8}$. La flora la recolecta y clasifica con la asesoría del médico y botánico francés Aimé Bonpland (1773-1858). A pesar de su muy buena disposición para el contacto humano, sin importar la condición social o racial, Humboldt nunca se vio tentado de retratar a nadie y las únicas imágenes indígenas como protagonistas corresponden a una traslación al grabado coloreado de unas figuras de madera tallada, vestidas se- gún tradición michoacana, en México (Humboldt, 1810, 274-275; Catlin, 1989-1990, 68; Buntix, 1994, I, 77)9.

Se ha dicho repetidas veces que Humboldt puso en movimiento a numerosos artistas europeos a quienes comprometió en la tarea ingente de ilustrar su obra (Löschner, 1988-1989). Las fuentes iconográficas las ofrecia él: en primera instancia, muchas de su propia mano (bosquejos al lápiz hechos in situ) ${ }^{10}$; otras, las menos, facilitadas por dibujantes y pintores conocidos en su travesía ( $v$.gr. Ignacio Castera y Ximeno y Planes en México). Entre los artistas con que se relacionó, hubo quienes lo retrataron: en Quito, José Cortés de Alcocer (act. 1750-1801), a quien pagó en 1801 el doble de lo acordado por lo complacido que quedó (Jesualdo y otros, 1968, III) ${ }^{11}$; en Nueva España, lo retrató, junto a sus instrumentos científicos, Rafael Ximeno y Planes (1759-1825) ${ }^{12}$. En Venezuela, se cree que Juan Lovera (1776-1841) pudo haberlo retratado (Duarte, 1985). Sin embargo, además de que el supuesto retrato no aparece, para la fecha de la estadía del naturalista en Caracas, Lovera apenas se desprendía del taller de su maestro An-

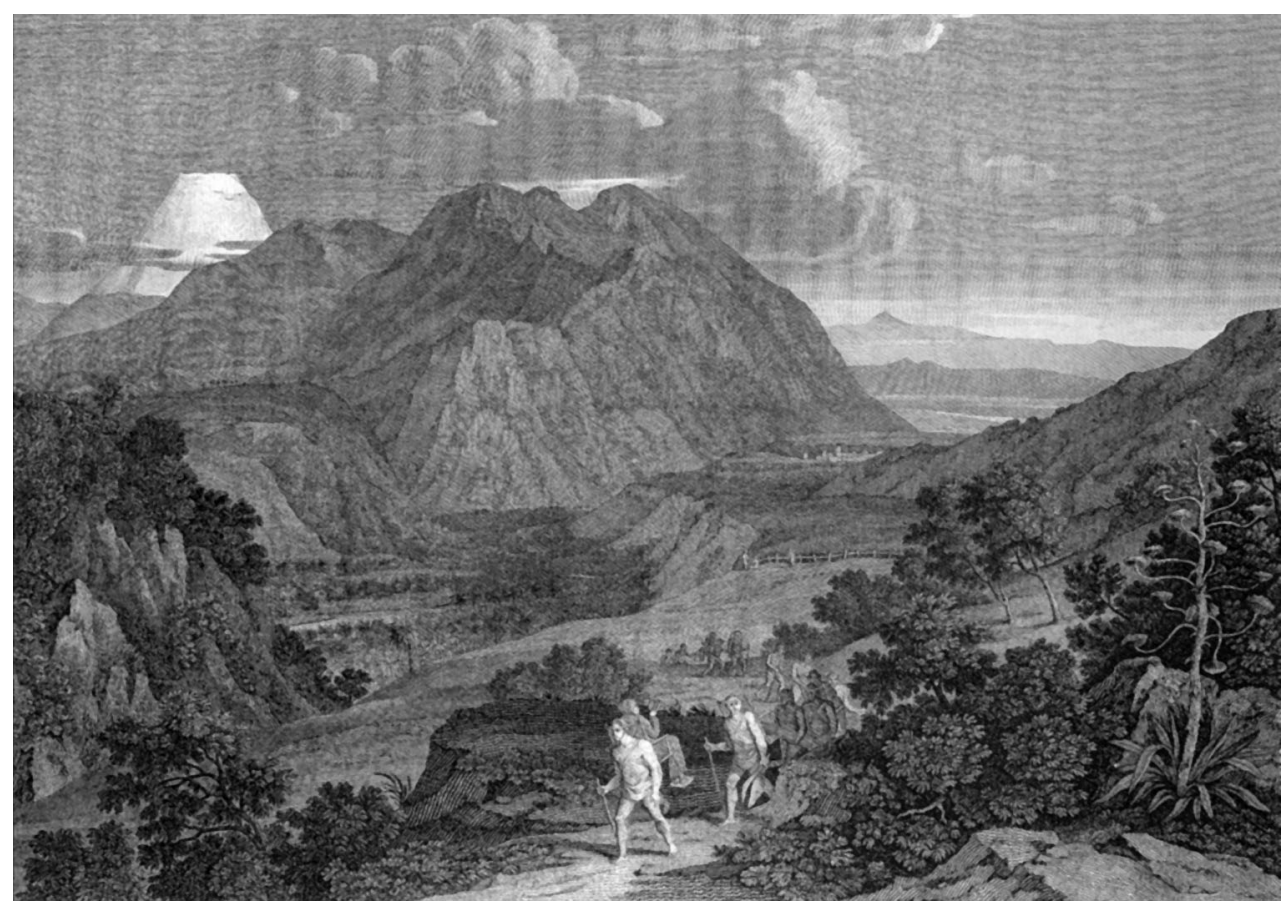


tonio José Landaeta (act. 1748-1799), pintor religioso por excelencia, y al mismo Lovera se le conoce como retratista sólo después de la guerra de Independencia ${ }^{13}$.

En cuanto a las ilustraciones para su obra, la misma formación artística de Humboldt le permitió controlar la calidad de las mismas, todas en la técnica que mejor conocía: el grabado en cobre, a veces coloreado a mano. Así se explicaría que no hubiese acudido nunca a la litografía, técnica que se fue imponiendo en la prensa y sobre todo en los libros ilustrados.

Así pues, a partir de la publicación en 1810, de sus Vue des cordillères et monuments des peuples indigènes de I'Amérique, "Humboldt fijó preceptos valederos hasta más allá de la segunda mitad del siglo XIX para la concepción y realización artística de libros científicos de viaje" (Löschner, 1988-1989, 9). Por otra parte, estimuló a varios artistas europeos para que rehicieran sus pasos a fin de que, con una mejor preparación y siguiendo sus indicaciones, contribuyeran a impulsar el género del paisaje como medio para divulgar una moderna sensibilidad en relación con la naturaleza. La ilusión de Humboldt era ofrecer a los artistas un terreno casi virgen en la historia del arte europeo, que se correspondiera con su propio tratamiento estético (que no poético) de la materia científica. No es casual que mantuviese una estrecha vinculación con Johann Wolfgang von Goethe (1749-1832), para quien también la naturaleza era un todo armónico (Moheit, 1993, 99-106).

No obstante, a raíz de la guerra de Independencia desatada en los lugares visitados, esa tarea tendrá que esperar. Ninguna otra razón permite entender por qué un Johann Moritz Rugendas (1802-1858) viajara primero al Brasil, como dibujante adscrito a una expedición científica, antes de aventurarse en las colonias hispanoamericanas en conflicto (Diener, 1997).

\section{IDEAS de Humboldt en toRno al PAISAJe}

Será apenas hacia la mitad del siglo XIX cuando el sabio alemán, ya radicado en su ciudad natal, Berlín, luego de una fructífera y larga permanencia en París -capital entonces de las ciencias-, publique su obra mayor, Cos- $\operatorname{mos}^{14}$. Aquí, finalmente, sistematiza sus ideas en torno a la "influencia de la pintura de paisaje en el estudio de la naturaleza". Para Humboldt la pintura de paisaje puede ser un auxiliar en la contemplación de la fisonomía de las plantas en los diferentes espacios de la Tierra; favorece la afición a los viajes lejanos; invita de manera instructiva y agradable a entrar en comunicación con la naturaleza libre. Se lamenta que desde la antigüedad se haya limitado a ser fondo de composiciones históricas o para adorno incidental en las pinturas murales. En este sentido expresa la necesidad de dar un giro:

"La historia del arte nos enseña el progreso en virtud del cual el accesorio ha llegado a ser poco á poco el principal objeto de la representación; cómo la pintura de paisaje, desligada del elemento histórico, ha tomado importancia y llegado á formar un género aparte, y cómo las figuras humanas no han servido desde entonces sino para animar una comarca cubierta de montañas ó de bosques, las calles de un jardín ó la orilla de un mar. Asi se ha preparado paulatinamente la separación de los cuadros de historia y de paisaje, cuya separación ha favorecido el progreso general del arte en las diferentes épocas de su desarrollo" (Humboldt, 1874, 73).

Reconoce sólo en el siglo XVII un interés auténtico en el paisaje con Claude Lorrain (1600-1682), Jacob van Ruysdael (1628-29-1682), Nicolás Poussin (1594-1665) y otros pocos. Pero les encuentra una limitación: se han ocupado sólo de representar zonas del viejo continente: norte de Europa, Italia meridional y Península Ibérica. Rescata en cambio a dos paisajistas holandeses olvidados que estuvieron en Brasil, Frans Post (1612-1680) y Albert van Eckhout (act. 1635-1664). Ahora los nuevos modelos serian Rugendas, Bellermann, Edward Hildebrand (1818-1869), Carl Nebel (1800-1865) y Albert Berg (1825-1884) "pintores del trópico al servicio de una idea fisionomica-geográfica" (Beck, 1988-1989, 13).

Humboldt cree fervientemente que la pintura de paisaje avanzará cuando "los artistas de genio salven con más frecuencia los estrechos límites del Mediterráneo", a fin de "abrazar la misma variedad de la naturaleza en los valles húmedos de los trópicos, con la frescura de un alma pura y joven" (Humboldt, 1874, 82).

Hay un motivo muy personal en esta postura: Humboldt se lamenta de que la mayoría de las expediciones ape- 
Ian a dibujantes seleccionados al azar, sin la competencia adecuada, quienes sólo al final de la travesía adquieren algún talento en la representación. Además, los viajes de circunvalación -que él mismo quería realizar en un principio- "ofrecen a los artistas raras ocasiones de penetrar en los bosques, llegar al curso de los grandes ríos y trepar á los vértices de las cadenas interiores de las montañas" (Humboldt, 1874, 82).

Humboldt se atreve a recomendar a estos artistas que trabajen en el sitio, "poseído[s] de emoción sobre los lugares mismos", trayendo "imágenes exactas de las cosas", de manera que no recurran al expediente de las obras de botánica o los invernaderos.

Con el fin de la guerra de Independencia hispanoamericana, crece en Humboldt la confianza en que la paz facilitará el progreso de las ciencias y de las artes. Sueña con esas ciudades de la América del Sur, situadas en altiplanicies andinas, donde "la vista percibe todas las variedades vegetales que se deben a la diversidad de los climas" (Humboldt, 1874, 82). Y define para él, lo que es el objeto de la pintura de paisaje:

"El azul del cielo, la figura de las nubes, los vapores que se forman alrededor de los objetos, el brillo del follaje y el contorno de las montañas, son los elementos que constituyen el aspecto general de una comarca. Abarcar este aspecto y reproducirlo de una manera precisa, tal es el objeto de la pintura de paisaje" (Humboldt, 1874, 87).

Por último trae a colación el tema de la daguerrotipia, con la que un género de pintura ilusionista (la pintura circular de Parker), proporcionaba -según Humboldt-, mejor que cualquier escenografía teatral, la sensación de estar realmente inmerso en un paisaje, con lo que "puede uno casi dispensarse de viajar por lejanos climas". Claro, esos panoramas circulares deben contar con un buen diámetro para que puedan cumplir su cometido, y hasta entonces habían representado sólo ciudades o lugares habitados. Asimismo, considera que la daguerrotipia funciona "no para [reproducir] la espesura del follaje, sino los troncos gigantescos de los árboles y la dirección de sus ramas". Concluye proponiendo que en cada ciudad, junto a los museos, se ofrezcan "panoramas con cuadros circulares de paisaje de diversa latitud y longitud". Las exposiciones internacionales de la segunda mitad del siglo XIX en Eu- ropa y Estados Unidos, alcanzaron a satisfacer este ideal ilusionista (Riccini y Marogna, 1981, 130-150).

Hoy es común apreciar en la obra de Humboldt, particularmente en Viaje a las regiones equinocciales del Nuevo Mundo, Vistas de las Cordilleras, Cuadros de la naturaleza y Cosmos, ejemplos de una prosa científica de alto valor literario, que hizo posible una comprensión moderna de la unidad física de la tierra. En este sentido, fue consecuente con una de las ideas más caras de la llustración: divulgar la ciencia (Tienmann, 1993, 107-116). E igualmente concibió la pintura del paisaje, con un carácter ilustrativo (Beck, 1993).

\section{LA EXPERIENCIA VENEZOLANA}

A semejanza de otros países americanos salidos de la guerra de Independencia, las circunstancias socioeconómicas no favorecieron de inmediato las ideas de Humboldt en Venezuela. Un primer intento de cartografiar la Gran Colombia, con el ingeniero militar Agustín Codazzi (17931859) como geógrafo y Carmelo Fernández como ilustrador, queda frustrado ante la inminencia del fin de esta unión de repúblicas. A partir de 1831, ya independiente Venezuela de la antigua Colombia, la Sociedad Económica de Amigos del País -institución oficial que agrupaba ciudadanos notables para el estímulo de las artes y las industrias-, promueve el necesario recuento de lo que habiamos sido desde el descubrimiento y con qué contábamos como recursos naturales. Dos libros se publicaron al cabo de la década: el Resumen de la historia de Venezuela, de Ramón Díaz Martínez (ca. 1810-1875) y Rafael María Baralt (1810-1860), y el Atlas físico y político de la República de Venezuela, de Agustín Codazzi. Ambos trabajos, publicados en París ostentan ilustraciones de Carmelo Fernández, particularmente el primero, basado en retratos.

Carmelo Fernández, sobrino del general José Antonio Páez, se había formado en Estados Unidos e incorporado a su regreso a la milicia, donde mejoró su formación en el campo de la cartografía. Alcanzó una alta estima oficial ya que su experiencia en París lo familiarizó con la litografía, técnica tempranamente usada por nuestra prensa (Calzadilla, 1981). En 1842, con motivo de la repatriación de los restos de Simón Bolívar, Carmelo Fernández 
fue encargado de registrar gráficamente los principales momentos. Lamentablemente no se llegaron a publicar todos sus dibujos, concebidos en su origen para servir de ilustración a la crónica oficial encargada a Fermín Toro. Las circunstancias políticas lo obligan a emigrar a Bogotá y alli se reencuentra con Codazzi. El entonces presidente neogranadino, José Hilario López (1789-1869), ordena la formación de una Comisión Corográfica que dé cuenta de las riquezas de Colombia, sus paisajes, sus artesanías, sus tipos raciales, sus accidentes geológicos, sus testimonios prehispánicos; en fin, todo aquello que pudiese contribuir a una idea concreta de lo que es el país (Giraldo Jaramillo, 1978).

Carmelo Fernández trabaja como acuarelista desde principios de 1850 hasta fines de 1851, en dos expediciones que recorren la parte noroccidental de Colombia (figs. 2 y 3): la primera le lleva a las provincias de Vélez, Socorro, Soto, Ocaña, Pamplona y Santander; la segunda a Tundama y Tunja. Al retirarse, lo sustituyen sucesivamente, un cartógrafo colombiano, Manuel María Paz (1810-1902) y un comerciante inglés, músico y aficionado a la pintura, Enrique Price (1819-1863). Ninguno de los dos alcanzó el nivel de calidad de Fernández.

Casi como repitiéndose el destino de la Expedición Botánica de Mutis, al concluir los trabajos de esta Comisión -por la muerte de Codazzi en 1859-, los materiales recogidos no recibieron una publicación oficial. Varios miembros de la
Comisión (científicos, historiadores) hubieron de publicar, cada uno por su cuenta, su relato de viaje pero sin ilustraciones. Sólo hacia fin de siglo la crítica llamó la atención sobre el valor documental y artístico de las acuarelas de Fernández (Girón, 1891). Al contrario del modelo de Humboldt, Fernández dio un gran lugar a la representación de los habitantes, destacando sus vestimentas y fisonomías, con cierta idealización. Por la representación artificial de los diversos tipos raciales, algunas imágenes recuerdan los cuadros de castas del siglo XVIII, más cuando en esas imágenes se les relaciona con una determinada artesanía, comercio o labrantía.

Por desgracia, Carmelo Fernández se dedicó con posterioridad más a la docencia artística y de idiomas, y sólo hacia la década del setenta, siendo funcionario en la ciudad de Maracaibo (Edo. Zulia), retoma sus pinceles y elabora una serie de seis grandes cuadros al temple $(180 \times 143 \mathrm{~cm})$ obedientes a los requisitos de Humboldt en cuanto a la representación de la naturaleza en sus diversos climas ${ }^{15}$. Sólo uno de estos cuadros introduce un elemento de ficción romántica, el referido a la Guajira: en el centro del grupo familiar indígena aparece una mujer blanca que parece provenir del socorrido tema de las cautivas. Ya el mismo Rugendas -que presenció un "malón" o entrada violenta de indígenas en campo criollo- lo había pintado en 1845 y 1848 , y al final del siglo XIX se había convertido en un tema académico en la pintura uruguaya (Juan Manuel Blanes, 1830-1901) y argentina (Ángel Della Valle,

2. Carmelo Fernández Páez, Vista del Nevado de Chita. Acuarela sobre papel, 1850-1851.

En: Álbum de la Comisión Corográfica de Colombia, 1853. Biblioteca Nacional, Bogotá.

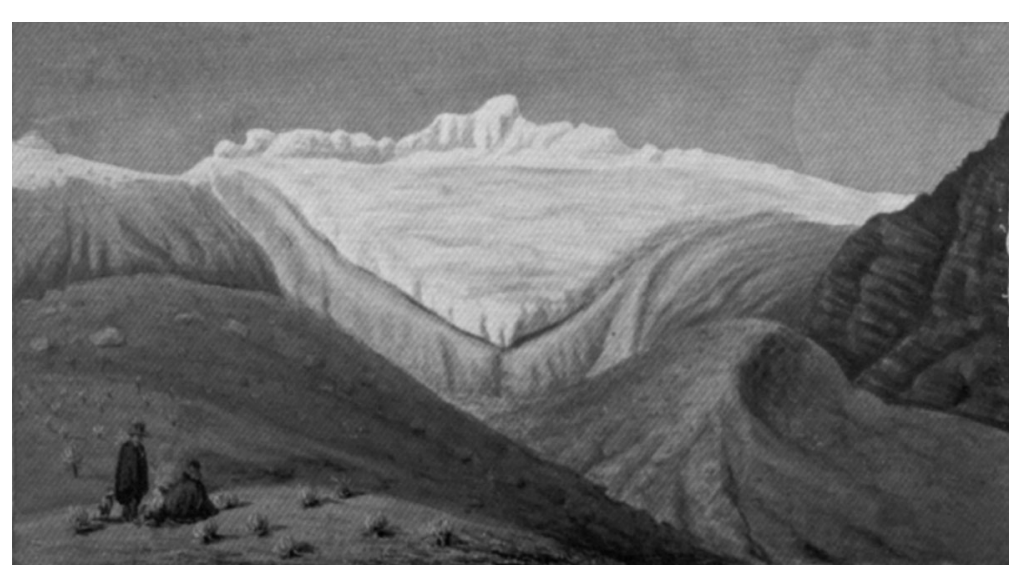


3. Carmelo Fernández Páez, Velez, Estrecho de Furatena en el Río Minero. Acuarela sobre papel, 1850-1851.

En: Álbum de la comisión Corogáfica de Colombia, 1853, Biblioteca Nacional, Bogotá.

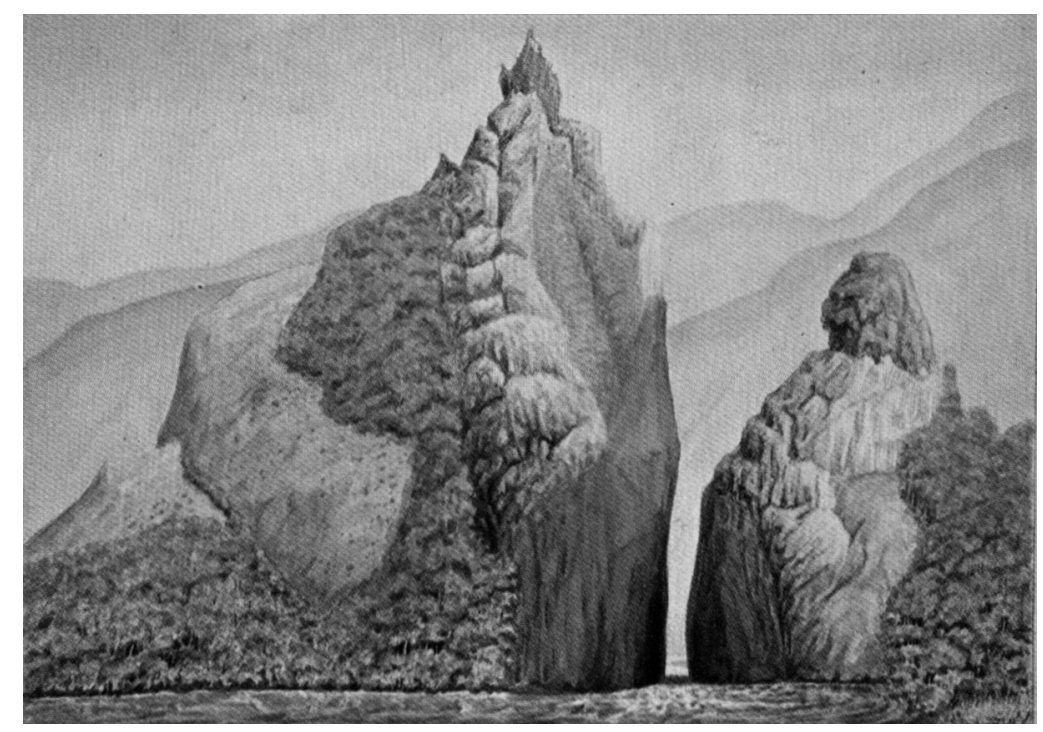

1852-1903). El tema había proliferado en la literatura romántica desde La cautiva, 1837, del argentino Esteban Echeverría (1805-1851) hasta Tabaré, 1880, del uruguayo Juan Zorrilla de San Martín (1857-1931) (Malosetti, 1994, II, 299-307). La diferencia estaria en que la imagen del venezolano Carmelo Fernández no es violenta sino pacífica, de integración social.

La segunda mitad del siglo XIX en Venezuela está marcada por la Guerra Federal y por los gobiernos liberales. Dentro de ese nuevo clima de progreso que se instaura, particularmente, desde 1870 con la llegada al poder del general Antonio Guzmán Blanco (1829-1899), puede decirse que vuelve a darse en el país un abierto apoyo a las artes y las ciencias. La paz guzmancista permite el ingreso de capitales extranjeros, el desarrollo de la prensa y, por ende, la creación de un público ávido de imágenes litografiadas que revelen la variedad y adelanto del país. Como anticipo de esta empresa situamos, ya desde Barcelona, al oriente del país, a la familia Bolet con la revista El Oasis (1856): padre médico y dos hijos: uno escritor y político, Nicanor (18381906), el otro dibujante y pintor, Ramón. Instalados en Caracas, los hermanos Bolet Peraza son responsables de la revista El Museo Venezolano, que se publicará en 1865. Se les asocia el litógrafo Henrique G. Neun (1827 ca.-1893).
Al año siguiente ofrecen a su clientela un Album de cromolitografías, ya aparecidas en la revista y ahora coleccionable. Las estampas reproducen, preferentemente, paisajes urbanos, donde la arquitectura domina. Pensar que en toda la ilustración de las obras de Humboldt, salvo las ruinas prehispánicas, sólo aparece la Plaza Mayor de México como vista urbana, y el dibujo se debe a un artista local, si bien de origen español: Rafael Ximeno y Planes, ya citado.

A inicios de esa misma década, ha llegado un digno sucesor de Humboldt al pais, el doctor Adolf Ernst (1832-1899), quien casi de inmediato atrae gente interesada en la ciencia y, especialmente, en la botánica. En 1867 se crea la Sociedad de Ciencias Físicas y Naturales de Caracas, donde participan, por ejemplo, el médico, historiador y anticuario Arístides Rojas (1826-1894) y el ornitólogo, taxidermista y pintor alemán Anton Goering, enviado del Museo Británico. Otro personaje, el comerciante inglés James Mudie Spence ( +1878$)$ entra en tratos y se anima con las excursiones al cerro del Ávila. Entre ellos está Ramón Bolet Peraza, como ilustrador. En 1872, antes de la partida de Mudie Spence -quien ha venido con intereses mineros-, se organiza, en el Café del Ávila, una Primera Exhibición de Bellas Artes con las obras que ha recolectado en su estadía, más otras que son añadidas para la ocasión. El artista más representado 
es Ramón Bolet: de un total de doscientas treinta obras, treinta y siete le corresponden.

En Manchester, en 1873, se exhiben unas ciento cincuenta obras del artista venezolano, entre acuarelas y dibujos (Key Ayala y Tello, 1957; Esteva-Grillet, 2001, I, 254-279). Un crítico e historiador eminente, John Ruskin (1819-1900), profesor en Oxford, se interesa en el personaje:

"Los dibujos han llegado, y el papel plateado me ha vuelto loco, pero a pesar de ello, he sacado la conclusión que los dibujos son en realidad buenos y llenos de sentimientos y fuerza. Los retratos son en verdad maravillosos. Pero Mr. Bolet debe venir a este pais a estudiar, pues no podrá progresar donde se encuentra -o al menos estará perdiendo un tiempo precioso-. Un poquito de estudio y lo colocaría en terreno firme" (Cit. Pineda. 1991, 51).

Mudie Spence convence al artista venezolano para que viaje a Oxford, previo contrato según el cual, a su regreso, pintaría según lo que deseara su financista ${ }^{16}$. La estadía se prolonga por ocho meses: la nostalgia y la salud lo trajeron de vuelta, para fallecer poco tiempo después, con apenas cuarenta años, en 1876, dejando viuda y ocho hijos. El libro de Mudie Spence, The land of Bolivar, or war and peace in the Republic of Venezuela, se publica con ilustraciones de Bolet, grabadas por A. Pateson ${ }^{17}$.

Lamentablemente, toda la producción llevada al exterior por este comerciante se perdió. Sólo se ha podido rescatar un álbum de dieciocho acuarelas que realizara a solicitud del entonces representante de la corona británica, R. T. C. Midleton. Entre estas imágenes es posible vislumbrar lo que pudo haber sido Ramón Bolet de no haber fallecido prematuramente. Allí encontramos sus paisajes más modernos, aunque todos atenidos a la idea del retrato de un lugar específico, incluso con un carácter documental ilustrativo: escenas ambientadas en la selva, en el llano o el campo, para presentar los diversos productos de exportación (cueros, cacao, café), con una visión pormenorizada de las plantas, más un curioso "bodegón" con paquetes recién desembarcados como símbolo del comercio (figs. 4 y 5); asimismo vistas de Caracas, Ciudad Bolívar, Maracaibo, La Orchila y La Guaira.

La única imagen que escapa a esa suerte de recreo en las riquezas venezolanas, es la correspondiente a la guerra civil, como para decir: esto es lo que impide que se desarrolle el comercio. Esta imagen realista recuerda una más primitiva pero igual de dolorosa: la que realizara sobre el tema de la epidemia de cólera en 1854 (antigua colección de Aristides Rojas, hoy en la Fundación John Boulton, Caracas) ${ }^{18}$. En ambas imágenes se vislumbra un propósito realista (en el sentido dramático) que se suavizó en la ilustración científica y pintoresca y la crónica costumbrista o celebrativa. En la herencia familiar del artista también se ha conservado una libreta de dibujos, entre los cuales hay paisajes correspondientes a Inglaterra (una marina, un castillo), más cercanos a un gusto plenamente romántico, antes que ilustrativo.

Dentro de la escasa y poco conocida obra de Ramón Bolet Peraza, resulta poco menos que excepcional el cuadro al óleo representativo del Mercado de San Jacinto (colección Odalys de Saravo): por la técnica, el formato y la minuciosidad, aplicada tanto al entorno arquitectónico como al

4. Ramón Bolet Peraza, Recolectores de cacao. Acuarela sobre papel. Colección privada, Caracas.

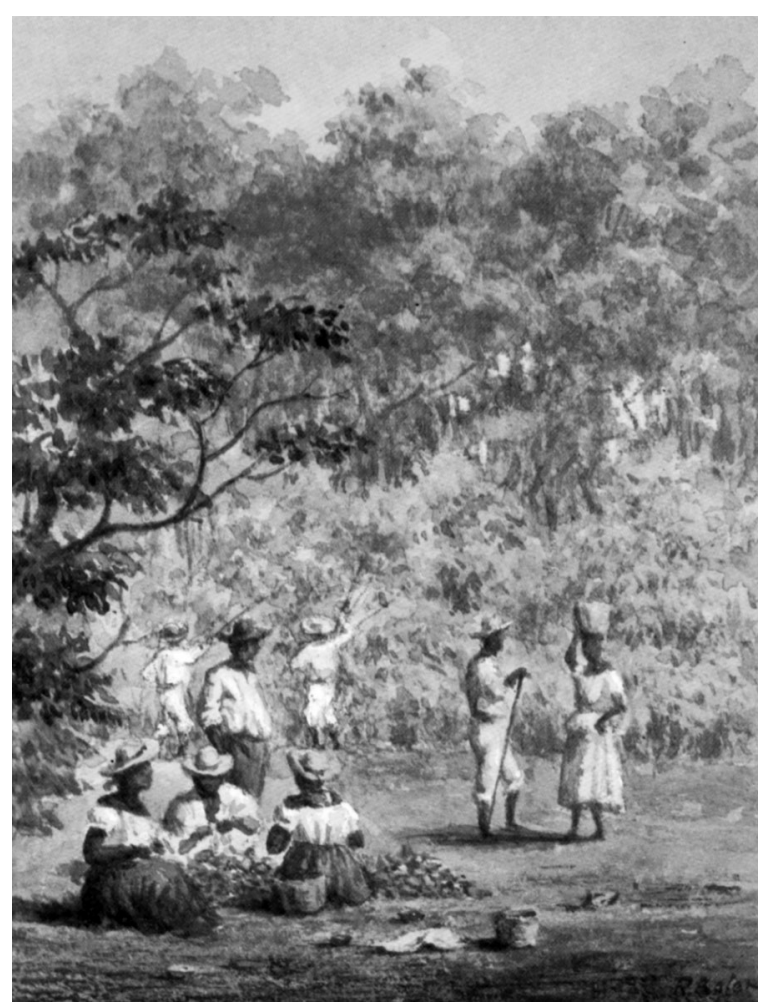


5. Ramón Bolet Peraza, Cacao venezolano. Acuarela sobre papel. Colección privada, Caracas.

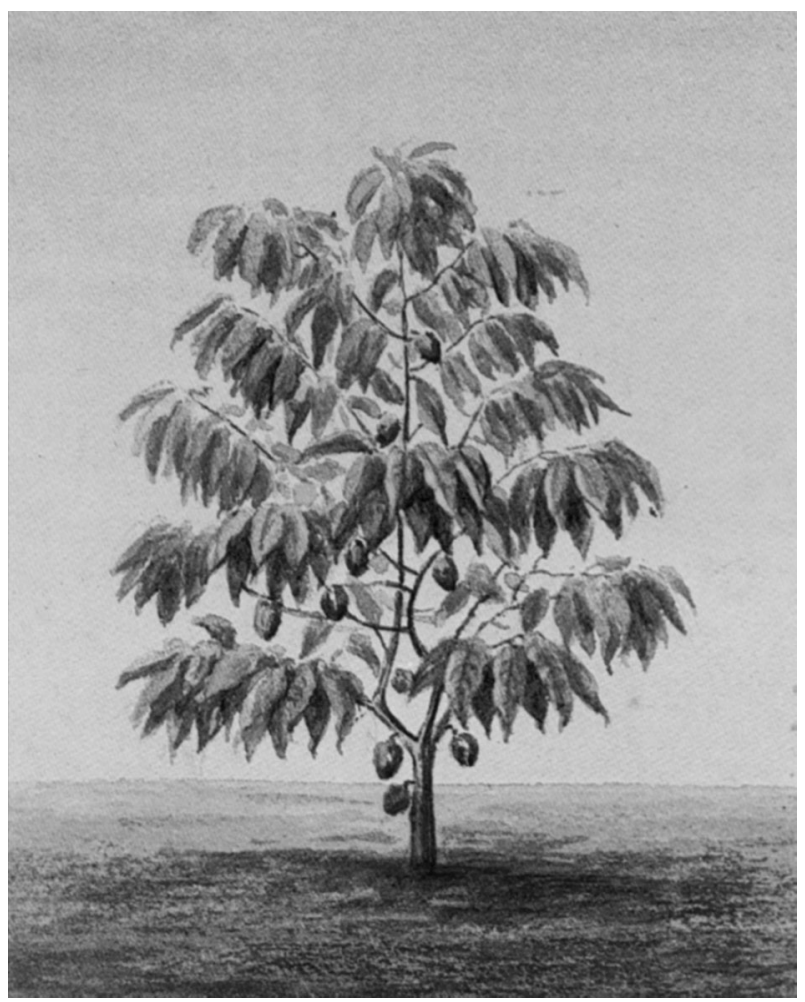

bien compuesto grupo de vendedores y compradores, entre mercancías. A un lado se capta, como testimonio elocuente de una época, el reloj de sol diseñado por Alejandro de Humboldt a solicitud de su anfitrión de la hacienda de Bello Monte, fuera de Caracas, y hoy conservado en el Museo Bolivariano.

Bolet se había iniciado en los misterios de la química por cuanto su padre era un dedicado farmaceuta; de allí le resultó fácil interesarse en la fotografía. En sus imágenes cromolitografiadas es evidente su apoyo en esta técnica. Posterior a su muerte, se publicó una segunda serie de cromolitografías, con el título de Album de Caracas y Vene- zuela (1878). Pero, es muy posible que la desproporción de las figuras y la arquitectura se deban atribuir a otra mano (Erminy, 1991) ${ }^{19}$. Sin duda, al decir de Juan Calzadilla, fue Ramón Bolet "uno de nuestros mejores dibujantes y tal vez el más notable acuarelista venezolano del siglo XIX" (Calzadilla, 1991, 17).

\section{Conclusiones}

Durante el siglo XIX, tanto en Europa como en América, prosperó el interés por el paisaje; sin embargo, dadas las circunstancias derivadas de la guerra de Independencia en las colonias hispánicas, los artistas nativos se dedicaron más a los retratos, a los cuadros de historia y, eventualmente, al costumbrismo. La asociación de dos de ellos, Carmelo Fernández Páez y Ramón Bolet Peraza, con empresas científicas, permitió el que algunas de las ideas de Humboldt contribuyeran al descubrimiento del paisaje con un carácter fisionómico e ilustrativo; aun así, pareciera que -tal como ocurría en Europa- para el público general resultara más interesante conocer las particularidades sociales antes que los accidentes naturales, 0 , en el mejor de los casos, las caracteristicas de sus ciudades antes que la de sus campos, y todo esto resuelto a través de la litografía, preferiblemente.

El desarrollo del paisaje en el caso venezolano fue pues, muy lento y sólo al final del siglo XIX se pueden atisbar inquietudes académicas por un paisaje realista, alejado ya de la visión topográfica de ciudades: un Tovar y Tovar o un Arturo Michelena. No tuvimos un representante criollo del paisajismo al óleo, de la categoría del mexicano José María Velasco (1840-1912) (Altamirano Piolle, 1993) o del ecuatoriano Rafael Troya (1845-1920) (Kennedy Troya, 1994 y 1999), pero la obra modesta de los venezolanos Carmelo Fernández Páez y Ramón Bolet Peraza que hemos estudiado, hace honor a las ideas de Humboldt en torno a una visión fisionómica de la naturaleza y en tal sentido constituye un valioso aporte a la construcción del imaginario del país. 
1 Dos exposiciones organizadas por el Instituto Iberoamericano Patrimonio Cultural Prusiano, de Berlin, han recorrido algunas ciudades de nuestro subcontinente: Artistas alemanes en Latinoamérica, Caracas, Museo de Bellas Artes de Caracas, 1979 y Alexander von Humbodt, inspirador de una nueva ilustración de América, Bogotá, Biblioteca Luis Ángel Arango, 1988-1989. Y con el apoyo del gobierno alemán, Lufthansa, la Asociación Venezolana-alemana para el Fomento Cultural, el Goethe-Institut y la Asociación Cultural Humbodtl, se hizo la exposición El asombro: viaje de Humboldt y Bonpland por Venezuela, Caracas, Galería de Arte Nacional, 1999.

2 En 2007, la Galería de Arte Nacional publicó la traducción al castellano de los Diarios venezolanos 18421845 de Bellermann, con el apoyo de la Fundación Wolmer, la Fundación Heriberto y Lisetotte Thiel, el Banco Mercantil, el Deutsch Bank, el Goethe-Institut y la Asociación Cultural Humboldt.

3 Goering vivió ocho años en Venezuela y relató sus vivencias en el libro Von tropischen Tieflande zum Ewigen ScheneeVenezueal. Eine malerische Schildering des schösten Tropenlandes Venezuela (1892), que ilustró con 54 imágenes; traducción al castellano de María Luisa G. de Blay (1962); hay nueva edición de lujo, con ilustraciones a color y traducción de Nora López y Verónica Jaffé (1993).

4 Con motivo del bicentenario del nacimiento del Libertador Simón Bolívar, se realizaron sendas exposiciones en Caracas y Bogotá: Carmelo Fernán-

Recibido: 6 de marzo de 2008 Aceptado: 10 de mayo de 2008
1982-1983 y Carmelo Fernández, pintor grancolombiano, Museo de Arte Moderno de Bogotá, 1983.

5 Hasta ahora no se ha dedicado suficiente atención museográfica a Bolet, aunque se reprodujo en 1968 el Album de Caracas y Venezuela, y también existe ya un libro de varios autores sobre su obra con excelentes reproducciones (AA.W., 1991). La trayectoria artística y vital de Bolet ha sido objeto de una recopilación documental multicopiada por parte de José María Salvador (1998).

6 La serie, "Trajes y frutos del Ecuador", firmada y fechada en 1783 , consta de seis cuadros y pertenece al Museo de América de Madrid.

7 Estudió el grabado en cobre con Daniel Chodowiecki, expuso en la Academia de Bellas Artes de Berlín entre 1786 y 1788 , y a su regreso de América continuó sus estudios en París bajo la guía del pintor neoclásico Francisco Gérard (1770-1837), a través de quien conoció la obra de Eugenio Delacroix (1798-1863). La estrecha relación con Gérard se revela en el frontispicio diseñado por éste para el Atlas géographique e phisique du Nouveau Continent, de 1814 (tomo XVIII de su obra Voyage aux régions équinoxiales du Nouveau Continent); cfr. Kügelgen (1997, 167182).

8 Esta edición príncipe incluyó 69 ilustraciones (grabados en cobre); la edición en cuarto, de 1813, llevaba sólo 19, "plusieurs colorés".

9 Las figurillas habian sido obsequiadas por Humboldt a la reina de Prusia, y ella las había mandado a dibujar.

10 Como se sabe, parte de la biblioteca y manuscritos de Humboldt se perdieron a causa de un incendio cuando se exhibian para subasta, de allí la rareza de los dibujos conservados en 
la Biblioteca Estatal de Berlín, de la que proviene el diseño de Gérard, ya citado, y otros examinados por el historiador chileno Miguel Rojas-Mix (1988, 84, nota 11).

11 Véase su reproducción, según copia de 1944 hecha por el pintor alemán Carl Sigmund von Sallwürck, en Alejandro de Humbodt. La naturaleza, idea y aventura $(1993,57)$. Eduardo Röhl $(1983,13)$ reproduce un retrato similar pero Humboldt aparece con los brazos cruzados y con nudo de corbata sencillo; realizado también en Quito, lo atribuye a Rafael Sabas (¿o Salas?), posiblemente sea una versión de mediados de siglo del original de José Cortés de Alcocer.

12 El retrato pertenece a la Universidad Nacional Autónoma de México.

13 Existe en la Fundación del Banco Industrial de Venezuela, Caracas, una copia al óleo de un retrato de Humboldt, con la firma de Arturo Michelena, pero no convence su autoría. La imagen corresponde al retrato hecho por Emma Gaggioti-Richards, en 1855, y grabado por Paul Habelmann.

14 En 1845 aparece el primer tomo y en 1862 el quinto. La primera traducción castellana será de 1851-1852.

15 Según Juan Calzadilla, -quien rescatara esos cuadros del abandono oficial en 1968-, la tradición los atribuía a Anton Goering (Calzadilla, 1983). La serie de seis, se redujo a cuatro por incuria gubernamental. Curioso que alguien le haya, a su vez, atribuido a Carmelo Fernández, la obra de Pedro Castillo: según Eduardo Picón Lares, Carmelo Fernández "decoró la residencia de Páez en Valencia" (Picón Lares, 1940).

16 Ese contrato fue un "artificio" del inglés para llevarlo a Inglaterra: el artista era de temperamento delicado, modesto y tenía familia nu- merosa (Bolet Peraza, 1895; AA.W., 1991, 61).

17 Se ignora la fecha de la primera edición; esta segunda, de 1878 , es póstuma al mecenas y al artista.

18 Reproducida en El Cojo Ilustrado, año 1, N. 14, Caracas, 24 de julio de 1892 , 252.

19 Según observación de Alejandro Salas, este segundo Album debe atribuirse sólo al dibujante y litógrafo Neun (AA.W., 2005, II, 908).

\section{BIBLIOGRAFÍA}

Altamirano Piolle, Maria Elena (1993): José María Velasco. Homenaje nacional, Museo Nacional de Arte, Ciudad de México.

AA.W. (1999): El asombro. Viaje de Humboldt y Bonpland por Venezuela, Galería de Arte Nacional, Fundación Cultural Chacao, Caracas.

AA.W. (2005): Diccionario biográfico de las artes visuales en Venezuela, Galería de Arte Nacional, Caracas.

Beck, Hanno (1979): "El arte descubre un continente. Sudamérica a través de la 'fisionómica' de Alexander von Humboldt", en Artistas alemanes en Latinoamérica, Museo de Bellas Artes, Caracas.

Bellermann, Ferdinand (2007): Diarios venezolanos. 1842-1845, Galería de Arte Nacional, Caracas.

Bolet Peraza, Nicanor (1895): "Ramón Bolet", en Las tres Américas, Nueva York; ahora en AA.W. (1891): Ramón Bolet, cronista gráfico de la Venezuela del ochocientos, 1836-1876, Empresas Delfino, Caracas.

Boulton, Alfredo y Löschner, Renate (1977): Bellermann y el paisaje en Venezuela, 1842-1845, Asociación Cultural Humboldt y Fundación Neumann, Caracas.
Boulton, Alfredo y Weissgärger, Helga (1991): Ferdinand Bellermann. Memoria del paisaje, 1842-1845, Fundación Galería de Arte Nacional, Caracas.

Buntix, Gustavo (1994): "El indio alfarero como construcción ideológica. Variaciones sobre un tema de Francisco Laso", en AA.W.: Arte, historia e identidad en América. Visiones comparativas, I, Instituto de Investigaciones Estéticas, Universidad Nacional Autónoma de México.

Calzadilla, Juan (1981): El grabado en Venezuela (1978), Fundarte, Caracas.

Calzadilla, Juan (1982-1983): Carmelo Fernández. Testigo de lo real y de la historia, Galería de Arte Nacional, Caracas.

Calzadilla, Juan (1991): "Ramón Bolet", en AA.W., Ramón Bolet, cronista gráfico de la Venezuela del ochocientos, 18361876, Empresas Delfino, Caracas.

Cummins, Tom (1994): "De Bry and Herrera: 'Aguas Negras' or The Hundred War over an Image of America", en AA.W., Arte, historia e identidad en América. Visiones comparativas, I, Instituto de Investigaciones Estéticas, Universidad Nacional autónoma de México.

Diener, Pablo (1997): Rugendas, 1802-1858, Consejo de Empresarios de América e Instituto Goethe, São Paulo.

Duarte, Juan (1985): Juan Lovera, el pintor de los próceres, Fundación Pampero, Caracas.

Dupouy, Walter (1969): Venezuela de hace un siglo. Los cuadros de Antón Goering, Asociación Cultural Humbo$\mathrm{dt}$, Caracas.

Esteva-Grillet, Roldán (2001): Fuentes documentales y críticas de las artes plásticas venezolanas. Siglos XIX y $X X$, Consejo de Desarrollo Científico y Humanístico, Universidad Central de Venezuela, Caracas.

Fajardo de Rueda, Marta (1994): "La obra artística de la Real Expedición Bo- 
tánica del Nuevo Reino de Granada, 1783-1816", en AA.W., Arte, historia e identidad en América. Visiones comparativas., I, Instituto de Investigaciones Estéticas, Universidad Nacional autónoma de México.

Gasparini, Graciano (1967): "Opiniones sobre pintura colonial", en Boletín del Instituto de Investigaciones Históricas y Estéticas, 8, Facultad de Arquitectura y Urbanismo, Universidad Central de Venezuela, Caracas.

Gesualdo, Vicente y otros (1968): Enciclopedia del arte en América, Bibliográfica Omeba, Buenos Aires.

Giraldo Jaramillo, Gabriel (1959): "Humboldt y el descubrimiento estético de América", en El Farol, 181, Creole Petroleum Corporation, Caracas.

Giraldo Jaramillo, Gabriel (1978): Colombia en 1950. Acuarelas de la Comisión Corográfica, Librería Suramérica, Bogotá.

Girón, Lázaro María (1891): "Un recuerdo de la Comisión Corográfica", en Revista Literaria, 18; ahora en AA.W. (1983): Carmelo Fernández, pintor grancolombiano, Museo de Arte Moderno de Bogotá.

Goering, Anton (1892): Von tropischen Tieflande zum Ewigen ScheneeVenezuel. Eine malerische Schildering des schösten Tropenlandes Venezuela, Adalbert Fischer's Verlag, Leizig; traducido al castellano por María Luisa G. de Blay (1962): Venezuela, el más bello país tropical, Universidad de los Andes, Mérida, Vzla; y por Nora López y Verónica Jaffé (1993): Venezuela, el más bello país tropical, Playco Editores, Caracas.

Humboldt, Alexander von (1810): Vue des cordillères et monuments des peuples indigènes de l'Amérique, Imprimerie de J. H Stone (edición in-folio), París.
Humboldt, Alejandro de (1874): Cosmos. Ensayo de una descripción física del mundo (1845-1862), II, Imprenta de Gaspar y Roig, Madrid (traducción de Bernardo Giner y José de Fuentes).

Junquera, Juan José (1988): "La visión de América en la pintura colonial", en Cuadernos de Arte Colonial, 4, Museo de América, Madrid.

Kennedy Troya, Alexandra (1994): "Artistas y científicos. Naturaleza independiente en el siglo XIX en Ecuador. Rafael Troya y Joaquín Pinto", en AA.W., Arte, historia e identidad en América. Visiones comparativas. I, Instituto de Investigaciones Estéticas, Universidad Nacional Autónoma de México.

Kennedy Troya, Alexandra (1999): Rafael Troya. 1845-1920. El pintor de los Andes Ecuatorianos, Ediciones del Banco Central del Ecuador, Quito.

Key-Ayala, Santiago (1957): Folleto raro. Ilustraciones de Venezuela. Catálogo de obras de arte reunidas en dieciocho meses de viaje por aquella República (traducción del inglés por Jaime TeIlo, a partir de la edición original de Manchester, 1873), Ediciones Europa, Caracas.

Kügelgen, Helga von (1997): "La alegoria de América en el frontispicio del viaje de Humboldt y Bonpland", en AA.W., Alejandro de Humboldt en México. Museo del Ministerio de Hacienda y Crédito Público e Instituto Goethe, México.

Löschner, Renate (1988-1989): "Influencia significativa de Humboldt sobre la representación artística de Latinoamérica en el siglo XIX", en AA.W., Alexander von Humboldt, inspirador de una nueva ilustración de América, Biblioteca Luis A. Arango, Bogotá.

Malosetti Costa, Laura (1994): "El rapto de las cautivas: un aspecto erótico de la barbarie en la plástica rioplatense del siglo XIX", en AA.W., Arte, historia e identidad en América. Visiones comparativas, II, Instituto de Investigaciones Estéticas, Universidad Nacional Autónoma de México.

Mollet, Ulrike (1993): "Alejandro de Humboldt y sus contemporáneos", en AA.W., Alejandro de Humboldt. La naturaleza, idea y aventura. Proyect Argentur, Essen.

Pérez Silva, Yasminy y Pino Iturrieta, Elías (1993): Artistas y cronistas extranjeros en Venezuela, 1825-1899, Fundación Galería de Arte Nacional, Caracas.

Picón Lares, Eduardo (1940): "Prólogo", en Las memorias de Carmelo Fernández, Academia Nacional de la Historia, Caracas.

Pineda, Rafael (1991): "Prólogo al Album de Caracas y Venezuela" (1968), en AA.W.: Ramón Bolet, cronista gráfico de la Venezuela del ochocientos, 18361876, Empresas Delfino, Caracas.

Riccini, Raimondi y Marogna, Giannella (1981): "Paesaggi urbani del'Ottocento", en AA.W., Paessagio. Imagine e realtá, Galleria d'Arte Moderno, Bolonia.

Rohl, Eduardo (1983): Exploraciones famosos de la naturaleza venezolana (1948), Fundación de Promoción Cultural de Venezuela, Caracas.

Rojas-Mix, Miguel (1988): "Las ideas artístico-científicas de Humboldt y su influencia en los artistas naturalistas que pasan a América a mediados del siglo XIX", en Armitano Arte, 13, Armitano, Caracas.

Tienmann, Klaus-Harro (1993): "Alejandro de Humboldt, pionero en la popularización del la ciencia", en AA.W., Alejandro de Humboldt. La naturaleza, idea y aventura, Proyect Argentur, Essen. 